\title{
The Effect of Heat Waves and Drought on Surface Wind Circulations in the Northeast of the Iberian Peninsula during the Summer of 2003
}

\author{
Pedro A. Jiménez, ${ }^{*},+$ Jordi Vilà-Guerau de Arellano, ${ }^{\#}$ J. Fidel GonzÁlez-Rouco,* \\ Jorge Navarro, ${ }^{+}$JuAn P. Montávez,${ }^{@}$ Elena García-Bustamante, ${ }^{*},+$ And Jimy Dudhia ${ }^{\text {* }}$ \\ * Departamento de Astrofísica y Ciencias de la Atmósfera, Universidad Complutense de Madrid, Madrid, Spain \\ ${ }^{+}$División de Energías Renovables, CIEMAT, Madrid, Spain \\ \# Meteorology and Air Quality Section, Wageningen University, Wageningen, Netherlands \\ ${ }^{@}$ Departamento de Física, Universidad de Murcia, Murcia, Spain \\ ${ }^{\&}$ Mesoscale and Microscale Meteorology Division, National Center for Atmospheric Research, ** Boulder, Colorado
}

(Manuscript received 9 September 2010, in final form 31 March 2011)

\begin{abstract}
Variations in the diurnal wind pattern associated with heat waves and drought conditions are investigated climatologically at a regional level (northeast of the Iberian Peninsula). The study, based on high-density observational evidence and fine spatial-scale mesoscale modeling for the 1992-2004 period, shows that wind speed can decrease up to $22 \%$ under situations characterized by extremely high temperatures and severe drought, such as the European summer of 2003. By examining the role of the different atmospheric scales of motion that determine the wind diurnal variability, it is found that the 2003 synoptic conditions are the main driver for changes in the wind speed field. In turn, these changes are modulated by mesoscale circulations influenced by the soil moisture availability. The results have implications for broad regional modeling studies of current climate and climate change simulations in as much as the study demonstrates that a correct representation of local soil moisture conditions impacts atmospheric circulation and therefore the regional climate state.
\end{abstract}

\section{Introduction}

Extreme weather situations produce strong impacts on humankind activities (Easterling et al. 2000). The drought and heat wave that affected Europe in the summer of 2003 produced enormous socioeconomic implications (e.g., Vandertorren et al. 2004; Schär and Jendritzky 2004). The anticyclonic conditions and a deficit of soil moisture availability that already affected more than $80 \%$ of the continent in springtime (Loew et al. 2009) led to the extremely high surface air temperatures registered (Fink et al. 2004; Black et al. 2004; Fischer et al. 2007a,b). The temperatures were very likely the warmest since the year 1500 (Luterbacher et al. 2004).

\footnotetext{
** The National Center for Atmospheric Research is sponsored by the National Science Foundation.

Corresponding author address: Pedro A. Jimenez, Departamento de Astrofisica y CC de la Atmosfera, Faculatad de CC Fisicas, Universidad Complutense de Madrid, Avenida Complutense s/n 28040, Madrid, Spain.

E-mail: pedro.jimenez@fis.ucm.es
}

Up to now, little attention has been paid to relate the effects that these extreme weather situations produce on the diurnal evolution of thermodynamic variables near the surface. To our knowledge, there have not been previous studies relating seasonal climate changes to diurnal wind variability. Wind pattern modifications can only be understood climatologically by studying all relevant atmospheric scales of motion (from synoptic to mesogamma) since potential perturbations at one of these scales could lead to modifications in the flow pattern. In consequence, the originality of our research relies on the combination of a long-term period of study (from 1992 to 2004) with a very fine spatial scale resolution in modeling and observations. By so doing, we are able to encompass the interactions between all of the important scales with topographic and land use conditions, which are the crucial elements in determining the wind patterns near the surface.

The wind observations were acquired at 41 surface stations located over a complex terrain region in the northeast of the Iberian Peninsula (Jiménez et al. 2010b). Similar to other coastal regions (e.g., Bastin and Drobinski 2006), the interaction between the different atmospheric 
scales plays a remarkable role over the surface flow behavior, converting it into a suitable region for this investigation. The summer of 2003 has been selected for study owing to the high temperatures and extremely dry soil conditions that affected most of the European continent, including the area of study (Fink et al. 2004; Loew et al. 2009).

By spatially averaging long-term wind observations from a high-density network, we are able to obtain a statistically robust characterization of the diurnal wind pattern. The mean daily cycle during the summer of 2003 (June-August) is represented in Fig. 1a. The range of variability of the mean daily cycles calculated with the regional time series of independent summers with observations available (from 1992 to 2004) is also displayed. The wind cycle for the summer of 2003 shows lower values and falls outside of the climatological range of variability. Inspired by this finding, the main objective of this study is to analyze the relative contribution of the large-scale circulation and the dry soil conditions to the abnormally low wind speeds observed.

\section{Numerical experiments to reproduce the observed evidence}

The observations were taken from 1992 to 2004 at a total of 41 locations (inset in Fig. 2a). The wind is recorded at $10 \mathrm{~m}$ above ground level, except for 7 stations that have the sensor at $2 \mathrm{~m}$ (Jiménez et al. 2010b). The stations are located at different places ranging from mountain tops to narrow and wide valleys and, thus, are representative of the regional wind variability.

The simulations are performed at a high horizontal resolution of $2 \mathrm{~km}$ to obtain an accurate representation of the orography and the land use characteristics. To explore the influence exerted by the anticyclonic situation that contributed to the heat wave, the 13 summers with observations available are simulated, prescribing the soil moisture availability (SMA) to its climatological value. The numerical experiment was performed with the Weather Research and Forecast model (WRF) (Skamarock et al. 2005) and has been described in Jiménez et al. (2010a).

Briefly, the numerical experiment is designed with a total of four domains configured in two-way nesting so as to progressively reach the horizontal resolution of $2 \mathrm{~km}$. The largest domain is centered at $43^{\circ} \mathrm{N}, 2^{\circ} \mathrm{W}$ and presents a rectangular shape of approximately $2000 \mathrm{~km} \times$ $2000 \mathrm{~km}$, whereas the innermost domain covers the region of study at $2-\mathrm{km}$ horizontal resolution. The numerical experiment consists of a sequence of short WRF runs since this has been shown to outperform long-term continuous simulations (e.g., Lo et al. 2008). Jiménez
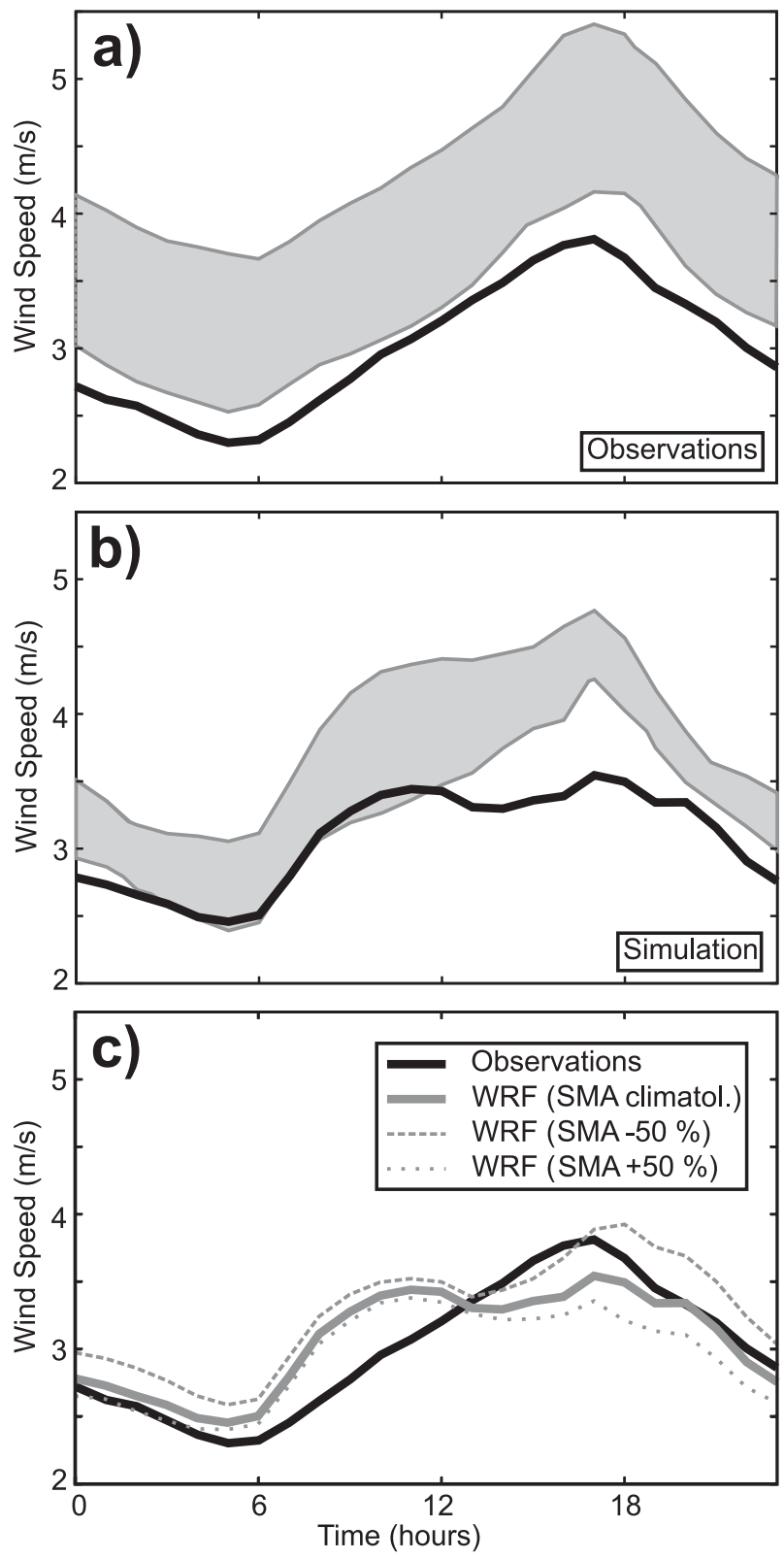

FIG. 1. (a) Mean daily cycle of the spatially averaged wind speed observed at the 41 stations during summer 2003 (black line). The gray-shaded area represents the range of variations of the mean daily cycles calculated using the wind speed observed during the 12 independent summers from 1992 to 2004 (excluding 2003). (b) As in (a) but calculated using the WRF simulation that imposed the climatological soil moisture during the years 1992-2004. (c) Mean daily cycle of the regional wind speed during 2003 calculated using observations and the different WRF simulations (see legend).

et al. (2010a) simulated the entire observational period, but only the parts of the simulation covering the summer months are employed in this investigation. Data from the 40-yr European Centre for Medium-Range Weather Forecasts Re-Analysis (ERA-40) project (Uppala et al. 


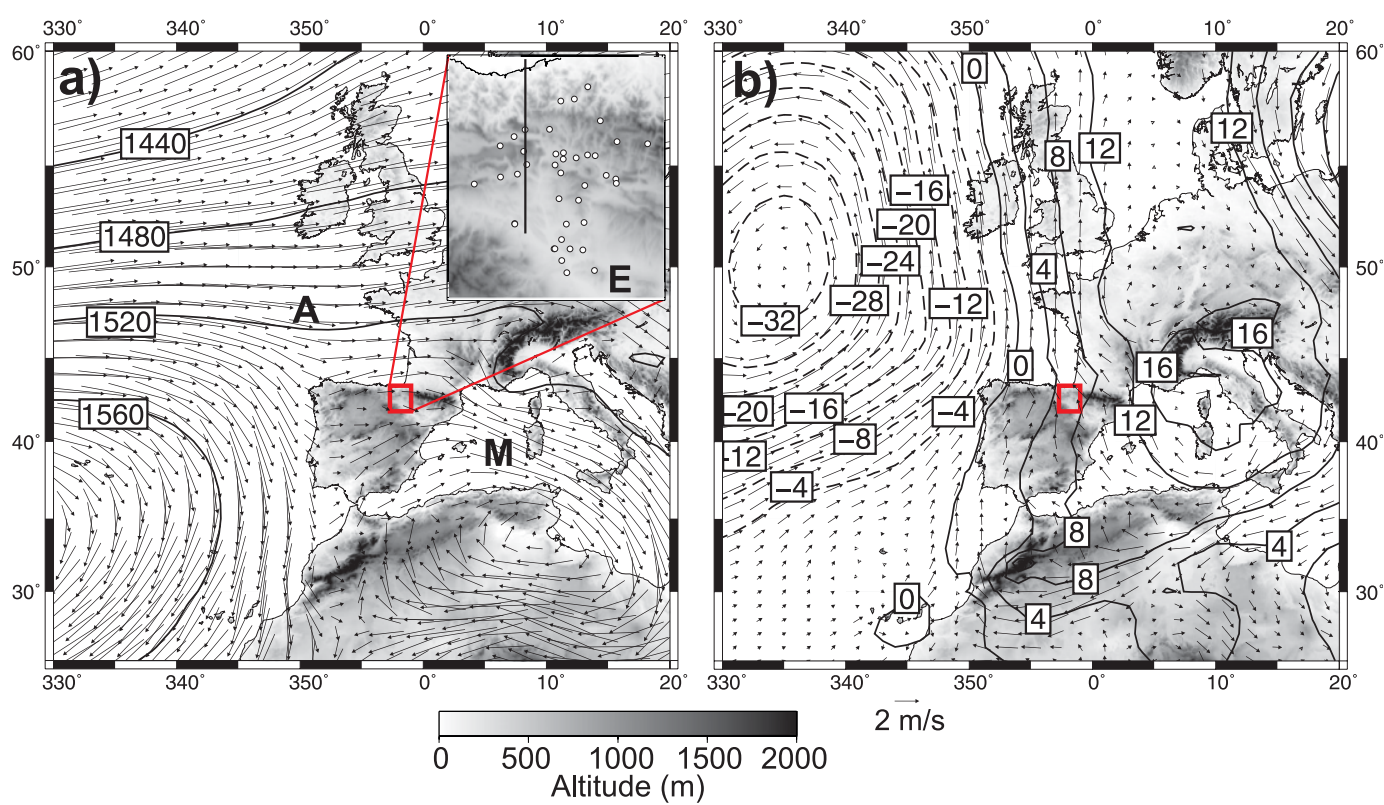

FIG. 2. (a) Mean geopotential height at $850 \mathrm{hPa}$ (contour lines) and mean horizontal wind (arrows) for the summers during the 1992-2004 period and (b) anomalies for the summer of 2003, both calculated using the ECMWF data. The red rectangle highlights the location of the study area; the inset in (a) shows the location of the 41 observational sites (circles), the Ebro valley (E), and of the cross section displayed in Fig. 3 (north-south straight line).

2005) and the operational analysis at the ECMWF (ECMWF data hereafter) at $1^{\circ}$ horizontal resolution are used as initial and boundary conditions. No nudging techniques were applied. For further details on the numerical experiment the reader is referred to Jiménez et al. (2010a).

The effects of drier soils associated with the drought are therefore neglected in the previous WRF simulation since the SMA is fixed to its climatological value during the entire integration time. More precisely, the SMA climatology is a function of the land-use type that, in this case, is based on the 24 categories classified by the U.S. Geological Survey, following Anderson et al. (1976). The influence that the drought produced on the surface circulations is explored by performing additional simulations for the summer of 2003, prescribing the SMA to values $50 \%$ higher and lower than the climatology.

\section{Synoptic contribution to the wind pattern}

The spatially averaged daily cycle of the wind speed obtained with WRF is shown in Fig. 1b. To mimic the observational network, the wind speed evolution is calculated with the simulated wind at the 41 observational sites during the summer of 2003. The range of variability of the mean daily cycles calculated with the regional series for the summers from 1992 to 2004 (excluding
2003) is also shown. The climatological wind variations reach a minimum (maximum) during the night (day) in concordance with observations (Fig. 1a). The range of variability is somewhat lower than the observed one. This indicates that the simulation reduces the interannual wind variability, a feature that is ultimately related with the smoother orography used in the experiment, which filters out the subgrid variability, and the use of constant SMA. The mean regional cycle for 2003 is, for most of the day, below the climatological range of variability. This finding provides the first indication of the role played by the large-scale circulation since no changes in the soil moisture were considered in this experiment.

The climatological surface circulations over the region are dominated by northwesterly flow (Jiménez et al. 2008, 2009). The anticyclonic circulations over the Atlantic (A in Fig. 2a) are channeled between the large mountain systems in the north of the Iberian Peninsula just where the region of study is located (Fig. 2a), over the Ebro valley $(\mathrm{E})$ and toward the Mediterranean Sea $(\mathrm{M})$. Under the presence of a low pressure system over the Mediterranean, the northwesterly circulations are intensified due to the pressure gradient generated over the valley as a consequence of the high pressures in the headlands and the low pressure in the valley mouth (García 1985; Jiménez et al. 2009). The intensity of the northwesterly 
circulations over the valley is therefore correlated with this pressure gradient (García 1985).

Figure $2 \mathrm{~b}$ shows the anomalies of the geopotential height at $850 \mathrm{hPa}$ during the summer of 2003. The pattern shows positive (negative) anomalies over the Mediterranean Sea (Atlantic) - the opposite pattern to the one that intensifies the climatological northwesterly circulations. Indeed, the horizontal wind anomalies are characterized by southeasterly circulations over the Ebro valley (Fig. 2b). The mean sea level pressure pattern shows a similar structure but the positive anomalies over the Mediterranean Sea are weaker. The pressure gradient over the Ebro valley calculated with pressure observations at Santander and Tortosa (García 1985) shows a reduction of $18 \%$ during 2003 in comparison with the mean gradient during the summers from 1992 to 2004 . Consequently, this weaker pressure gradient is the main contributor to lower wind speeds since both variables are correlated $(r=0.76)$. Notice, however, that this does not imply an explicit reduction of $18 \%$ of the wind speed.

\section{Sensitivity to soil moisture availability}

The effects that the drought produces over the diurnal wind pattern through mesoscale and smaller spatialscale motions are studied by performing two additional simulations for the summer of 2003 with a $50 \%$ higher/ lower SMA. The mean daily cycle obtained with the different simulations are displayed in Fig. 1c. The time series show a similar evolution until 1200 UTC when they start to diverge. A lower (higher) SMA leads to an increase (decrease) in the wind speed. A drier soil, more in concordance with the soil conditions of the summer of 2003 , leads to a wind speed maximum in the late afternoon that is more in agreement with the observed wind variations.

The physical processes responsible for the diurnal wind variations are better understood by analyzing the wind in a north-south vertical cross section over the region (line in Fig. 2a). The cross section shows the summer averages of the potential temperature and the vertical and meridional wind components at 1200 and 1800 UTC, for the different simulations performed for 2003 (Fig. 3). The planetary boundary layer (PBL) height calculated with the bulk Richardson number assuming a critical value of 0.25 is also displayed.

The averages at 1200 and 1800 UTC calculated with the simulation that prescribes the climatological SMA are displayed in Figs. 3a,b. Upper levels show southerly circulations over the entire cross section. At the surface, a different behavior of the flow is found at 1200 UTC (Fig. 3a). The coastal areas of the north show a seabreeze formation that favors northerly winds at the surface and the return flow at $\sim 1000 \mathrm{~m}$ AGL. On the contrary, the Ebro valley and the mountains show southerly circulations within the whole cross section. The mountain barrier intensifies both circulations at 1200 UTC due to the development of anabatic or upslope winds. These winds cannot be distinguished in the mean flow (Fig. 3a) but become evident in the cross section of the anomalies (not shown). Notice that the atmosphere over the Ebro valley is well mixed at 1200 UTC and shows a potential temperature of $303 \mathrm{~K}$ within the PBL that reaches $1500 \mathrm{~m}$.

Six hours later, at 1800 UTC, the PBL is lower (Fig. 3b) owing to the reduction of solar heating and, thus, the turbulent mixing. The decrease in the PBL height coincides with the intensification of the northern circulations responsible for the wind speed maximum noticed in the late afternoon. The sea-breeze circulation cell is still noticeable as well as another meridional circulation cell on the southern slopes of the mountains facing the Ebro valley that also contribute to the intensification of the flow in the late afternoon. The latter is associated with downslope, or katabatic winds.

The intensification of the sea-breeze front in the late afternoon has been previously noticed (e.g., Simpson et al. 1977; Physick 1980; Reible et al. 1993). Simpson et al. (1977) attributed the acceleration to the increase of the horizontal temperature gradient at the sea-breeze front due to the decrease in solar heating. The PBL is lower in areas closer to the sea; thus the sensible heat flux warms a thinner layer than over the areas with higher PBL. The decrease of solar heating in the afternoon reduces the heat flux, and the air advected by the sea breeze becomes colder at the front, thereby increasing the horizontal temperature gradient.

The interaction between surface processes, boundary layer dynamics, and mesoscale phenomena strongly depends on SMA. A reduction of moisture produces a higher PBL over the Ebro valley that reaches more than $1600 \mathrm{~m}$ at 1200 UTC (Fig. 3c). The atmosphere is again well mixed but a $1 \mathrm{~K}$ warmer $(304 \mathrm{~K})$ than the climatological simulation (Fig. 3a). The reason for this is the increase of the sensible heat flux to the detriment of latent heat flux as a consequence of the soil moisture reduction. The sea-breeze front at 1200 UTC is more intense as a consequence of the higher horizontal temperature gradient. This higher gradient also produces a stronger intensification of the sea breeze at 1800 UTC (Fig. 3d). The simulation performed with moister soil shows the opposite behavior, a lower $(1400 \mathrm{~m})$ and colder PBL $(302 \mathrm{~K})$ that leads to a weaker sea-breeze front at 1200 (Fig. 3e) and 1800 UTC (Fig. 3f). Hence, the reduction (increase) of the soil moisture produces a stronger (weaker) sea-breeze circulation that is ultimately 


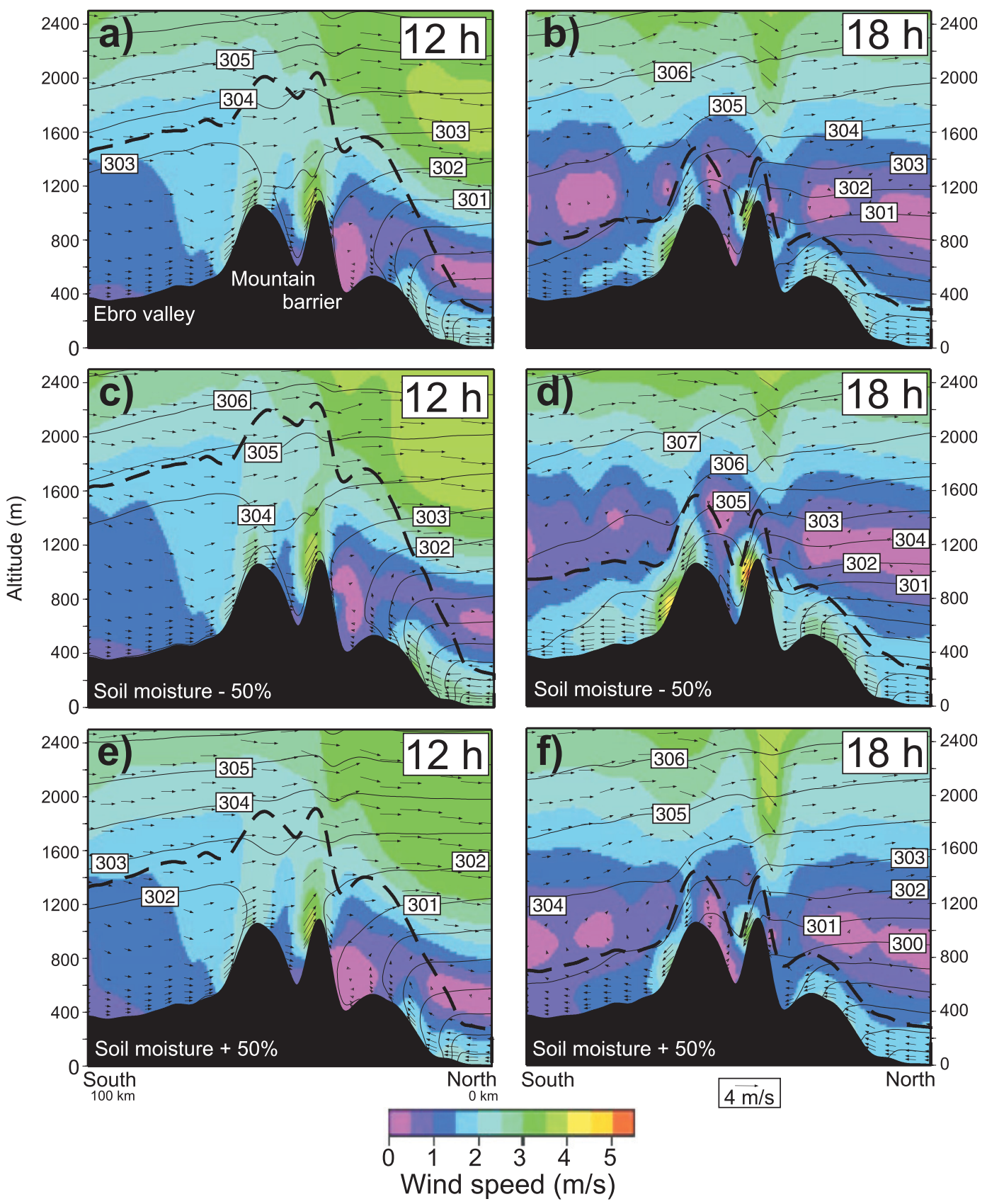

FIG. 3. South-north cross section showing the mean $v-w$ wind components (arrows) and mean potential temperature (contours) at (left) 1200 and (right) 1800 UTC in the summer of 2003 (June-August) for the WRF simulations performed with (top) SMA climatological values, (middle) $50 \%$ drier, and (bottom) $50 \%$ moister: the black dashed lines represent the PBL height. The mean $v$ wind component is highlighted by colored shading.

responsible for the different tendencies of the wind speed in the late afternoon (Fig. 1c). The regional averages calculated for a reduction versus an increase of the soil moisture differ by $0.7 \mathrm{~m} \mathrm{~s}^{-1}$ at 1800 UTC. This difference is largest in northern locations of the region that show greater than $1.1 \mathrm{~m} \mathrm{~s}^{-1}$. In consequence, the drier soils of summer 2003 contribute to an intensification of the regional wind speed and, therefore, can partially compensate the weaker wind pattern driven by the 2003 synoptic conditions.

A point that requires further investigation is the role of mesoalpha-scale phenomena in the diurnal wind variability. 
Drier soils could also strengthen the intensity of the Iberian thermal low (Haarsma et al. 2009), contributing to the intensification of the winds toward the interior of the peninsula during the day (Portela and Castro 1996). The influence of this phenomenon is investigated with an additional numerical experiment that solely reduces the SMA over the region of study (inset in Fig. 2a). Results show a very similar mean daily cycle to the one obtained after reducing SMA over all of the simulated domain (not shown). This indicates that the effects produced by the higher land-sea thermal contrast, due to the 2003 lower SMA, plays a more important role in intensifying the winds over the region of study than those associated with the thermal low enhancement.

\section{Summary and conclusions}

This observational and modeling study reveals that heat waves and droughts are able to modify surface wind variability. Both circulations induced by synoptic scale and by mesoscale patterns can potentially contribute to these variations. In the region under study for the summer of 2003, the large scale is most responsible for the abnormally low wind speeds observed (Fig. 1a), which are $22 \%$ lower than during the reference period (1992-2004). The positive (negative) pressure anomalies over the Mediterranean Sea (Atlantic Ocean) reduced the pressure gradient over the area, resulting in the low wind speeds recorded. Della-Marta et al. (2007) identified a similar sea level pressure pattern associated with heat waves over the Iberian Peninsula. Hence, similar situations to the case examined here for the summer of 2003 could be expected in the future.

The modifications introduced by mesoscale circulations operating at the mesogamma scale can be responsible for regional wind speeds that differ up to $20 \%$ (1800 UTC) when changes in the SMA are considered. This indicates that land-atmosphere interactions can potentially play an important role in controlling the surface wind climate through the smallest scales of motion. An appropriate simulation of the soil state is therefore necessary to have reliable estimates of the surface circulations of current climate or climate change scenarios. We advocate the need of fine spatial resolution in regions characterized by complex topography or heterogeneous surface properties so as to more accurately represent the circulations driven by the smallest atmospheric scale dynamics. To complete the understanding of surface wind patterns, the use of statistical downscaling techniques is useful to alleviate the computational demand required by high spatial resolution in the dynamical downscaling (e.g., García-Bustamante et al. 2011).
Acknowledgments. We thank the Navarra government and the ECMWF for providing us with the datasets used in this study. This investigation was partially supported by Projects CGL-2008-05093/CLI and PSE-120000-2008-9 and was accomplished within the Collaboration Agreement 09/490 between CIEMAT and NCAR as well as the Collaboration Agreement 09/153 between CIEMAT and UCM. We also thank the reviewers for their helpful comments.

\section{REFERENCES}

Anderson, J. R., E. E. Hardy, J. T. Roach, and R. E. Witmer, 1976: A land use and land cover classification system for use with remote sensor data. U.S. Geological Survey Professional Paper 964, 28 pp.

Bastin, S., and P. Drobinski, 2006: Sea-breeze-induced mass transport over complex terrain in south-eastern France: A casestudy. Quart. J. Roy. Meteor. Soc., 132, 405-423.

Black, E., M. Blackburn, G. Harrison, B. Hoskins, and J. Methven, 2004: Factors contributing to the summer 2003 European heatwave. Weather, 59, 217-223.

Della-Marta, P. M., J. Luterbacher, H. von Weissenfluh, E. Xoplaki, M. Brunet, and H. Wanner, 2007: Summer heat waves over western Europe 1880-2003, their relationship to large-scale forcings and predictability. Climate Dyn., 29, 251-275.

Easterling, D. R., G. A. Meehl, C. Parmesan, S. A. Changnon, T. R. Karl, and L. O. Mearns, 2000: Climate extremes: Observations, modeling, and impacts. Science, 289, 2068-2074

Fink, A. H., T. Brücher, A. Krüger, G. C. Lackebusch, J. G. Pinto, and U. Ulbrich, 2004: The 2003 European summer heatwaves and drought-Synoptic diagnosis and impacts. Weather, 59, 209-216.

Fischer, E. M., S. I. Seneviratne, D. Lüthi, and C. Schär, 2007a: Contribution of land-atmosphere coupling to recent European summer heat waves. Geophys. Res. Lett., 34, L06707, doi:10. 1029/2006GL029068.

— - _ P. L. Videle, D. Lüthi, and C. Schär, 2007b: Soil moisture-atmosphere interactions during the 2003 European summer heat wave. J. Climate, 20, 5081-5099.

García, L., 1985: La predicción del tiempo en el Valle del Ebro. INM Tech. Rep. Series A 38, 99 pp.

García-Bustamante, E., J. F. González-Rouco, J. Navarro, E. Xoplaki, P. A. Jiménez, and J. P. Montávez, 2011: North Atlantic atmospheric circulation and surface wind in the northeast of the Iberian Peninsula: Uncertainty and long term downscaled variability. Climate Dyn., doi:10.1007/s00382-010-0969-x, in press.

Haarsma, R. J., F. Selten, B. vd Hurk, W. Hazeleger, and X. Wang, 2009: Drier Mediterranean soils due to greenhouse warming bring easterly winds over summertime central Europe. Geophys. Res. Lett., 36, L04705, doi:10.1029/2008GL036617.

Jiménez, P. A., J. F. González-Rouco, J. P. Montávez, J. Navarro, E. García-Bustamante, and F. Valero, 2008: Surface wind regionalization in complex terrain. J. Appl. Meteor. Climatol., 47, 308-325.

,,--- E. García-Bustamante, and J. Navarro, 2009: Climatology of wind patterns in the northeast of the Iberian Peninsula. Int. J. Climatol., 29, 501-525.

- — - E. García-Bustamante, J. Navarro, J. P. Montávez, J. Vilà-Guerau de Arellano, J. Dudhia, and A. Roldan, 2010a: 
Surface wind regionalization over complex terrain: Evaluation and analysis of a high-resolution WRF numerical simulation. J. Appl. Meteor. Climatol., 49, 268-287.

, ——, J. Navarro, J. P. Montávez, and E. García-Bustamante, 2010b: Quality assurance of surface wind observations from automated weather stations. J. Atmos. Oceanic Technol., 27, $1101-1122$.

Lo, J. C.-F., Z.-L. Yang, and R. A. Pielke Sr., 2008: Assessment of three dynamical climate downscaling methods using the Weather Research and Forecasting (WRF) model. J. Geophys. Res., 113, D09112, doi:10.1029/2007JD009216.

Loew, A., T. Holmes, and R. de Jeu, 2009: The European heat wave 2003: Early indicators from multisensoral microwave remote sensing? J. Geophys. Res., 114, D05103, doi:10.1029/ 2008JD010533.

Luterbacher, J., D. Dietrich, E. Xoplaki, M. Grosjean, and H. Wanner, 2004: European seasonal and annual temperature variability, trends, and extremes since 1500. Science, 303, 1499-1503.

Physick, W. L., 1980: Numerical experiments on the inland penetration of the sea breeze. Quart. J. Roy. Meteor. Soc., 106, 735-746.
Portela, A., and M. Castro, 1996: Summer thermal lows in the Iberian Peninsula: A three-dimensional simulation. Quart. J. Roy. Meteor. Soc., 122, 1-22.

Reible, D., J. E. Simpson, and P. F. Linden, 1993: The sea breeze and gravity-current frontogenesis. Quart. J. Roy. Meteor. Soc., 119, 1-16.

Schär, C. and G. Jendritzky, 2004: Climate change: Hot news from summer 2003. Nature, 432, 559-560.

Simpson, J. E., D. A. Mansfield, and J. R. Milford, 1977: Inland penetration of sea-breeze fronts. Quart. J. Roy. Meteor. Soc., 103, 47-76.

Skamarock, W. C., J. B. Klemp, J. Dudhia, D. O. Gill, D. M. Barker, W. Wang, and J. G. Powers, 2005: A description of the Advanced Research WRF version 2. NCAR Tech. Note NCAR/TN-468+STR, 88 pp.

Uppala, S. M., and Coauthors, 2005: The ERA-40 Re-Analysis. Quart. J. Roy. Meteor. Soc., 131, 2961-3012.

Vandertorren, S., F. Suzan, S. Medina, M. Pascal, A. Maulpoix, J.-C. Cohena, and M. Ledrans, 2004: Mortality in 13 French cities during the August 2003 heat wave. Amer. J. Public Health, 94, 1518-1520. 